\begin{tabular}{|c|l|}
\hline Title & Stereochemical studies of hexylitaconic acid, an inhibitor of p53-HDM2 interaction \\
\hline Author(s) & Nakahashi, A tsufumi; Miura, Nobuaki; Monde, Kenji; Tsukamoto, Sachiko \\
\hline Citation & $\begin{array}{l}\text { Bioorganic \& Medicinal Chemistry Letters, 19(11), 3027-3030 } \\
\text { https://doi.org/10.1016/.bmcl.2009.04.057 }\end{array}$ \\
\hline Issue Date & 2009-06-01 \\
\hline Doc URL & http://hdl.handle.net/2115/38549 \\
\hline Type & article (author version) \\
\hline Additional Information & There are other files related to this item in HUSCAP. Check the above URL. \\
\hline File Information & 19-11_p3027-3030.pdf \\
\hline
\end{tabular}

Instructions for use 


\title{
Stereochemical studies of hexylitaconic acid, an inhibitor of p53-HDM2 interaction
}

\author{
Atsufumi Nakahashi, ${ }^{a}$ Nobuaki Miura, ${ }^{a}$ Kenji Monde, ${ }^{a,}$ and Sachiko Tsukamoto ${ }^{b}$ \\ ${ }^{\mathrm{a}}$ Graduate School of Advanced Life Science, Frontier Research Center for Post-Genome \\ Science and Technology, Hokkaido University, Kita-ku, Sapporo 001-0021, Japan \\ ${ }^{\mathrm{b}}$ Graduate School of Science, Chiba University, 1-33 Yayoi-cho, Inage-ku, Chiba \\ 263-8522, Japan
}

Footnote

Keywords: VCD; enantiomers; p53; HDM2; enantioseparation; $\alpha$-alkyl carboxylic acid Corresponding author. Tel. +81 11706 9041; fax: +81 11706 9042; e-mail:

\section{(Abstract)}

Hexylitaconic acid (1) is an intriguing natural product possessing a chiral carbon, and both its enantiomers have been found in nature. Enantiomeric pure $(+)-(\mathbf{1})$ and $(-)-(\mathbf{1})$ were successfully prepared by racemic synthesis followed by enantiomeric separation in a chiral HPLC system. Their absolute configurations were clarified by the vibrational circular dichroism technique using their methyl esters $\mathbf{2}$ and lactones $\mathbf{3}$. Their inhibitory activities against the interaction of p53-HDM2 were also examined. 
Itaconic acid is a structurally unique methylenesuccinic acid and frequently exists as its derivatives, which possess an $\alpha$-hydrocarbon chain, resulting a tertiary alkyl chiral carbon center. In general, optically active natural products have usually been found as a single enantiomer. ${ }^{1}$ Interestingly, hexylitaconic acid (1) has been found in nature as either enantiomer. (+)-1 was isolated as a root growth stimulator of lettuce seedlings from Aspergilus niger cultivated in field soil. ${ }^{2}(-)-\mathbf{1}$, on the other hand, was isolated as a metabolite produced by marine endophytic fungus Apiospora montagnei. ${ }^{3}$ Recently, Tsukamoto et al. succeeded in discovering that $(-)-\mathbf{1}$, which is derived from the culture broth of marine fungus, Arthrinium sp, functioned as an inhibitor of the p53-HDM2 interaction. $^{4}$

Although a variety of origins and significant bioactivities of $\mathbf{1}$ have been reported, the absolute stereochemistry of 1 remains ambiguous. In 1987, Isogai et al. reported its absolute configuration, which was determined on the basis of the Cotton effect in the CD spectrum of $\alpha$-methylene- $\gamma$-lactone derived from (+)-1 by partial esterification and reduction. ${ }^{5}$ However, the crucial intensity of the observed electronic circular dichroism was too small $(\Delta \varepsilon<1)$ to clearly assign its absolute configuration. No other reliable investigation concerning its absolute configuration has been performed. Moreover, since many biologically important $\alpha$-alkyl carboxylic acids, such as ceriporic acid ${ }^{6}$ and tensyuic acid, ${ }^{7}$ have recently been found in nature, more reliable and applicable methods to determine the stereochemistry of such derivatives would be desirable.

In this study, both enantiomers of $\mathbf{1}$ were prepared by chemical synthesis, and their inhibitory activities against the interaction of p53-HDM2 were investigated for the first time. Also, we applied the vibrational circular dichroism (VCD) technique to a hexylitaconic acid derivative to determine its absolute configuration as well as to 
attempt to establish a general chiroptical methodology for $\alpha$-alkyl carboxylic acid derivatives. VCD is an emerging technique used to determine the absolute configurations of various types of natural products ${ }^{8,9}$ by the direct comparison of observed VCD spectra with reliable density functional theory (DFT) calculations.

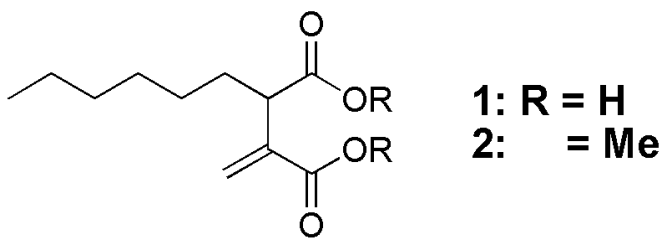

Racemic 1 was prepared by a three-step procedure from commercially available citraconic acid dimethyl ester. ${ }^{10}$ Racemic $( \pm)-\mathbf{1}$ was then subjected to chiral HPLC on a CHIRALPAK $^{\circledR}$ IA column $\left(0.46 \mathrm{~cm} \phi \times 25 \mathrm{~cm}, \mathrm{t}_{0}=7.0, \mathrm{t}_{1}=24.8, \mathrm{t}_{2}=26.3 \mathrm{~min}, \alpha=1.1\right.$ in hexane:2-propanol $=24: 1,0.3 \%$ acetic acid, $0.5 \mathrm{~mL} / \mathrm{min}$ ) to afford the first-eluted enantiomer $((-)-\mathbf{1})$ and the second-eluted one $((+)-\mathbf{1}) .{ }^{11}$ In solution, $\mathbf{1}$ has a possible form for complex aggregates through the intramolecular and/or intermolecular hydrogen bonds between the two carbonyl groups of $\mathbf{1}$. These aggregates could give complex VCD and IR spectra. Although there have been several profound studies simulating such self-associating molecules, ${ }^{12}$ theoretical predictions on these compounds remain complicated. We therefore decided to prepare the corresponding dimethyl ester (2) and performed VCD analysis on it in order to determine the absolute configuration of $\mathbf{1}$. The following methylation reactions of (-)-1 and (+)-1 were carried out at neutral $\mathrm{pH}$, since racemization is predicted to occur via keto-enol tautomerism under acidic or basic conditions, affording (-)-2 and (+)-2, respectively, without racemization. ${ }^{13}$

The IR and VCD spectra of each enantiomer were measured on a commercial Fourier 
transform spectrometer in $\mathrm{CDCl}_{3}$ solution through a $100 \mu \mathrm{m}$ path length cell with $\mathrm{CaF}_{2}$ windows. The IR spectra of $(-)-2$ and $(+)-2$ were identical each other, while their VCD spectra were obtained in the almost complete mirror images each other (Figure 1). Both enantiomers showed the characteristic VCD band around $1730 \mathrm{~cm}^{-1}(\mathrm{C}=\mathrm{O}$ stretch $)$ with several complex bands in the fingerprint region $\left(1300-1000 \mathrm{~cm}^{-1}\right)$.

Using molecular mechanics (MM) with MMFF94S force fields from the CONFLEX program, conformational analysis of $(R)-2$ was carried out using the DFT calculations with the $\mathrm{C}-\mathrm{C}-\mathrm{C}-\mathrm{C}$ angles in the alkyl chain being fixed to $180^{\circ}$. To obtain accurate energies and IR and VCD spectra of these conformers, geometrical optimizations and harmonic frequency analyses were performed using the DFT calculations at the B3PW91/6-311++G(d,p) level of theory for the 32 low-lying conformers. The total IR and VCD spectra were obtained by averaging with a Boltzmann weighted population derived from free energy with respect to the vibrational motion of the molecule. Fourteen conformers, whose cumulative sum of the Boltzmann weighted population is over $95 \%$, were used in the average. The frequencies of the spectra were scaled with a factor of 0.97 .

Figure 1 shows the comparison of IR and VCD spectra observed for (-)-2 with those calculated for $(R)$-2. Between the observed and calculated spectra, the signs of the major VCD bands showed reasonable agreement. In particular, the characteristic VCD absorption around $1730 \mathrm{~cm}^{-1}(\mathrm{C}=\mathrm{O}$ stretch $)$ was in a good agreement with the most stable conformer of $(R)$-2, which reliably verified that the absolute configuration of $\mathbf{2}$ is $R-(-) / S-(+)$. Consequently, the absolute configuration of hexylitaconic acid (1) was concluded to be $R-(-) / S-(+)$, since the conversion of 1 into 2 proceeds without inversion of the stereochemistry. The difference between the observed and theoretical VCD in the 
fingerprint region can be attributed to the contribution of the alkyl chain structure that was fixed to the zigzag conformation during the calculation.

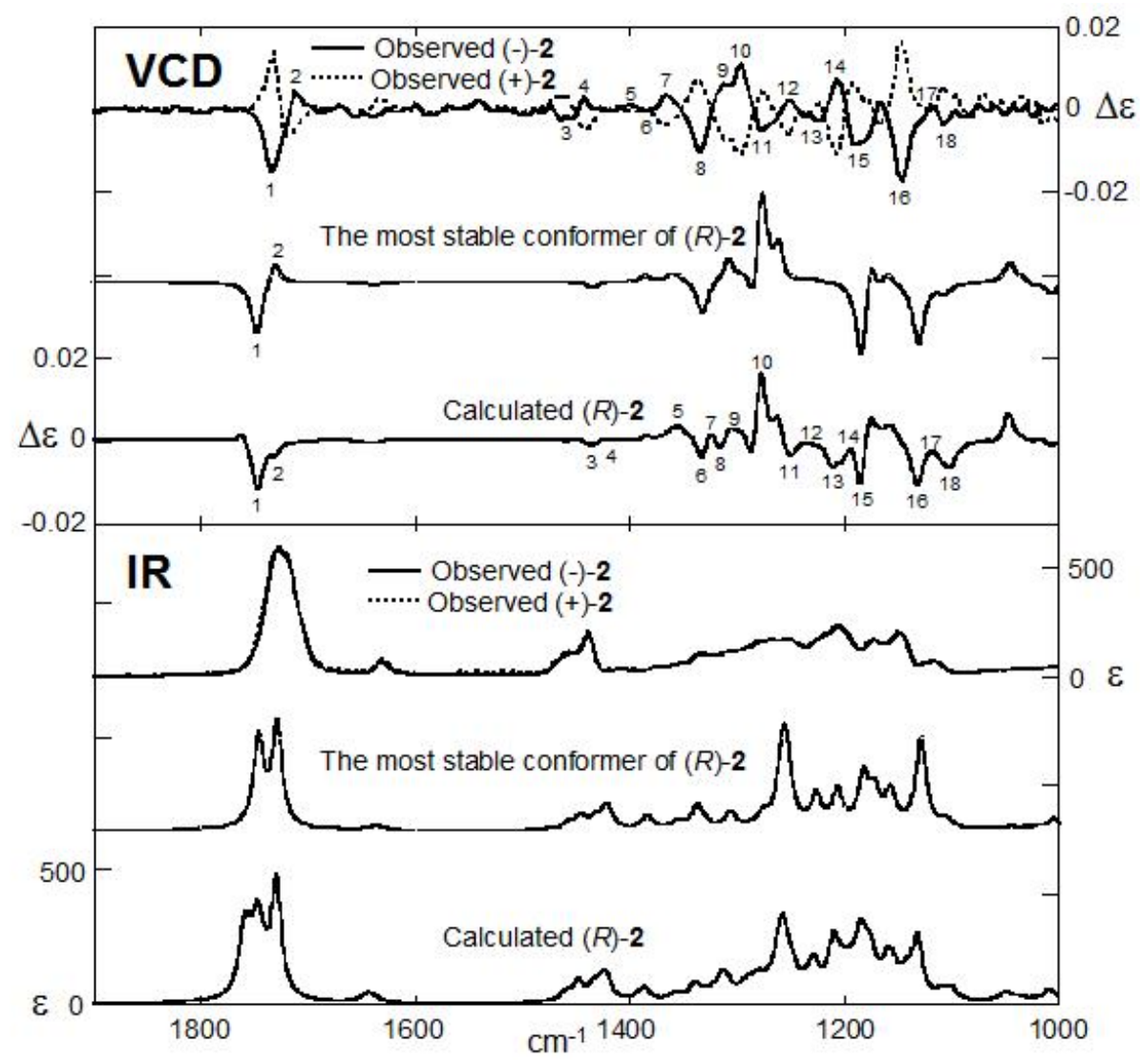

Figure 1. Comparison of IR (lower frame) and VCD (upper frame) spectra observed for (-)-2 with those calculated for $(R)-\mathbf{2}$. The number of the peak position is assigned as follows. First, by comparing the observed and the theoretical IR spectra, each IR peaks was assigned. Then, the peak positions of the VCD from each method were assigned so that they correspond to each IR peak position.

To reduce the number of the possible conformations in the parts of the alkyl side chain on the DFT calculation for the VCD study, acyclic compound $\mathbf{1}$ was converted into a cyclic compound $\mathbf{3}$ as a more rigid structure. Dicarboxylic acid $\mathbf{1}$ was selectively esterified to a racemic monomethylester $\mathbf{4}$ in acidic methanol. ${ }^{2}$ The ester group in $\mathbf{4}$ subjected to treatment with diisobutylaluminium hydride in dichloromethane followed 
by heating a resulting hydroxyl acid to be converted a lactone $3 .^{14}$ The racemic 3 was efficiently separated into each enantiomer in the chiral HPLC system on a CHIRALCEL ${ }^{\circledR}$ OB-H column. Each enantiomer of $\mathbf{3}$ showed completely mirror-imaged VCD spectra (Figure 2). ${ }^{15,16}$ The DFT calculation of $(R)$-3 was performed by the almost same method as that for $2 .{ }^{16}$ Figure 2 indicates an obvious identity in observed and calculated IR and VCD spectra of (+)-3 and (R)-3. Thus, it was undoubtedly confirmed that (+)-3 had an $R$ configuration. To verify stereochemical relationships of these chiral compounds, their derivatizations were performed. On the other hand, optically pure $(-)-\mathbf{4}^{15}$ was efficiently converted to $(R)-(+)-3$ by lactonization and to $(R)-(-)-2$ by $\mathrm{t}$ methylation, respectively (Scheme 1). ${ }^{16}$ This showed the chiral center of (-)-4 was deduced to be an $R$ configuration, supporting the result of the VCD study of the diester 2.

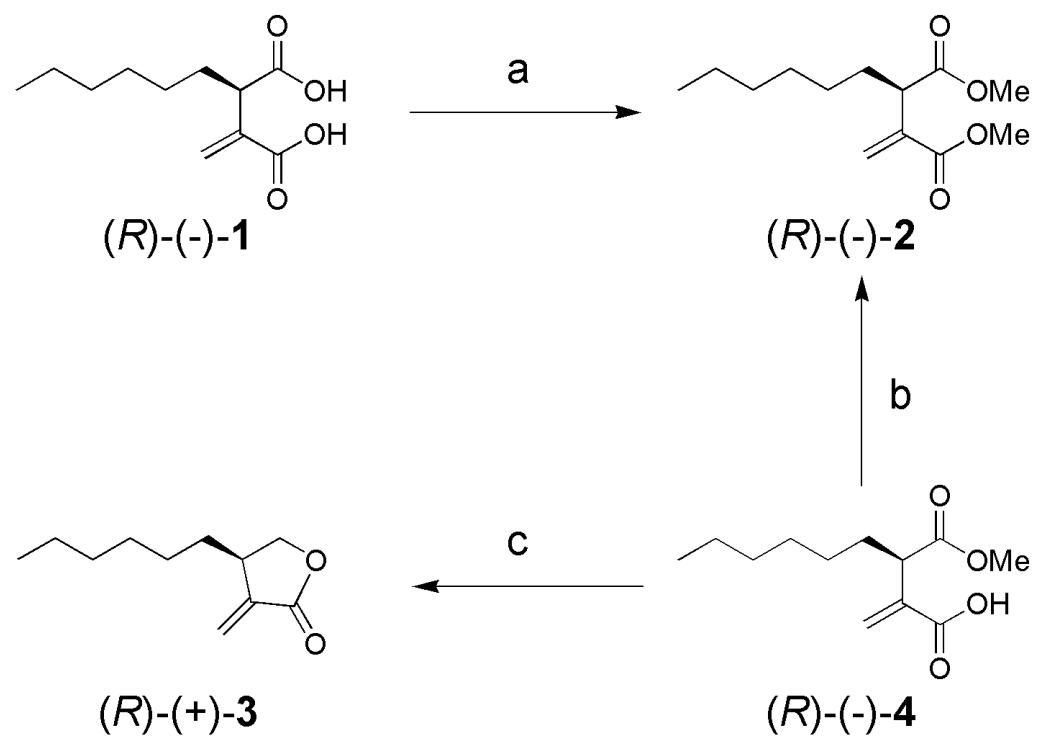

Scheme 1. Reagents and conditions: (a) TMS-diazomethane, $\mathrm{CH}_{2} \mathrm{Cl}_{2} / \mathrm{MeOH}(3 / 1), \mathrm{rt}, 0.5 \mathrm{~h}, 17 \%$;

(b) TMS-diazomethane, $\mathrm{CH}_{2} \mathrm{Cl}_{2} / \mathrm{MeOH}$ (3/1), rt, 10 min, 59\%;

(c) DIBAH, $\mathrm{CH}_{2} \mathrm{Cl}_{2},-78^{\circ} \mathrm{C}, 1 \mathrm{~h}$ then $\mathrm{CHCl}_{3}$, reflux, $16 \mathrm{~h}$, two steps, $35 \%$. 


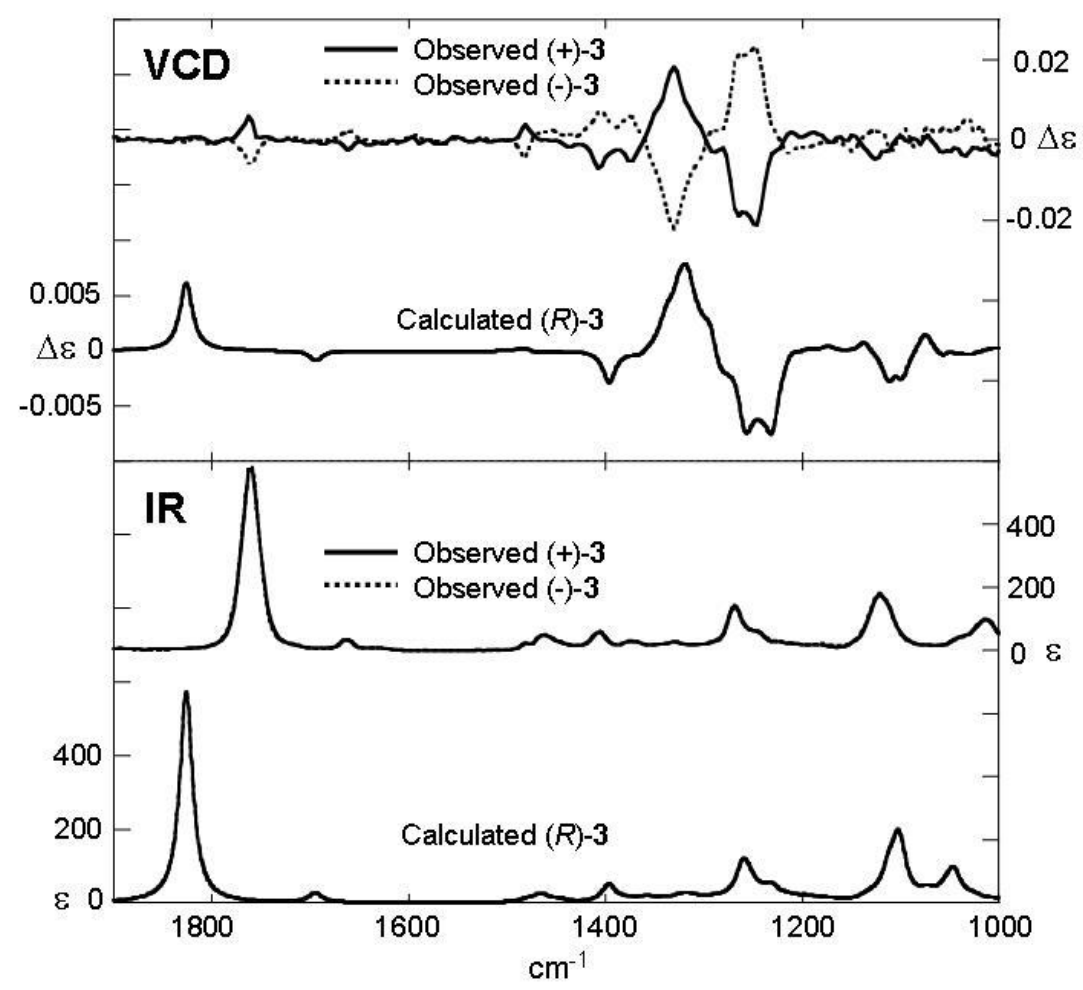

Figure 2. Comparison of IR (lower frame) and VCD (upper frame) spectra observed for (+)-3 with those calculated for $(R)-3$.

Finally, the p53-HDM2 binding assay was carried out. Inhibition of p53-HDM2 binding activity was examined by ELISA according to the standard procedure using purified recombinant p53 and HDM2 proteins and primary anti-MDM2 antibody (Santa Cruz, SMP14). (+)-1 inhibited the p53-HDM2 interaction in a dose-dependent manner and showed an $\mathrm{IC}_{50}$ of $50 \mu \mathrm{g} / \mathrm{mL}$ comparable to that of the (-)-enantiomer.

In conclusion, we have successfully determined the absolute stereochemistry of hexylitaconic acid (1) using its dimethyl ester (2) and its lactone derivative (3) to be $R-(-) / S-(+)$ by the VCD technique. This revealed the reliable stereochemical consequence for 1 as $(R)-(-)$ for the first time, which was opposite to the results previously assigned. ${ }^{5}$ This VCD study also suggests that the methodology described 
here can be applied to chiral analysis of other $\alpha$-alkyl carboxylic acids. In addition, $(+)$-hexylitaconic acid ((+)-1) was shown to have an inhibitory activity against the p53-HDM2 interaction, which was comparable to the reported value for the $(-)$-enantiomer ((-)-1).

\section{(Acknowledgments)}

We are very thankful to Prof. H. Yokosawa, Prof. S.-I. Nishimura, and Dr. T. Taniguchi at Hokkaido University for their helpful suggestions. This work was supported in part by a grant-in-aid for scientific research (Grants 20310127) and the Sapporo Biocluster "Bio-S", the Knowledge Cluster Initiative of the Ministry of Education, Sports, Science and Technology (MEXT). A. N. gratefully acknowledges a fellowship from the Japan Society of the Promotion of Science.

(Supplementary data)

Supplementary data associated with this article can be found, in the online version, at doi:10.1016/j.bmcl.XXXX.XX.XXX. 
(References and Notes)

(1) (a) Mori, K. Bioorg. Med. Chem. 2007, 15, 7505-7523. (b) Krastel, P.; Petersen, F.; Roggo, S.; Schmitt, E.; Schuffenhauer, A. Aspects of Chirality in Natural Products Drug Discovery. In Chirality in Drug Research; Francotte, E., Lindner, W., Eds.; Wiley-VCH: Weinheim, 2006; Vol. 33, pp 67-94

(2) Isogai, A.; Washizu, M.; Kondo, K.; Murakoshi, S.; Suzuki, A. Agric. Biol. Chem. 1984, 48, 2607-2609.

(3) Klemke, C.; Kehraus, S.; Wright, A. D.; Konig, G. M. J. Nat. Prod. 2004, 67, 1058-1063.

(4) (a) Tsukamoto, S.; Yoshida, T.; Hosono, H.; Ohta, T.; Yokosawa, H. Bioorg. Med. Chem. Lett. 2006, 16, 69-71. (b) Tsukamoto, S. J. Nat. Med. 2006, 60, 273-278.

(5) Isogai, A.; Sakuda, S.; Nakayama, J.; Washizu, M.; Shindou, K.; Watanabe, S.; Suzuki, A. Proceedings-Plant Growth Regulation Society of America 1987, 14th, 250-254.

(6) (a) Watanabe, T.; Teranishi, H.; Honda, Y.; Kuwahara, M. Biochem. Biophys. Res. Commun. 2002, 297, 918-923. (b) Enoki, M.; Honda, Y.; Kuwahara, M.; Watanabe, T. Chem. Phys. Lipids, 2002, 120, 9-21. (c) Amirta, R.; Fujimori, K.; Shirai, N.; Honda, Y.; Watanabe, T. Chem. Phys. Lipids, 2003, 126, 121-131. (d) Rahmawati, N.; Ohashi, Y.; Watanabe, T.; Honda, Y.; Watanabe, T. Biomacromolecules 2005, 6, 2851-2856. (e) Ohashi, Y.; Kan, Y.; Watanabe, T.; Honda, Y.; Watanabe, T. Org. Biomol. Chem., 2007, 5, 840 - 847.

(7) (a) Hasegawa, Y.; Fukuda, T.; Hagimori, K.; Tomoda, H.; Omura, S. Chem. Pharm. Bull. 2007, 55, 1338-1341. (b) Matsumaru, T.; Sunazuka, T.; Hirose, T.; Ishiyama, A.; Namatame, M.; Fukuda, T.; Tomoda, H.; Otoguro, K.; Omura, S. Tetrahedron 2008, 64, 7369-7377.

(8) (a) Freedoman, T. B.; Cao, X.; Oliveira R. V.; Cass, Q. B.; Nafie, L. A. Chirality 2003, 15, 196-200. (b) Lassen, P. R.; Skytte, D. M.; Hemmingsen, L.; Nielsen, S. F.; Freedoman, T. B.; Nafie, L. A.; Christensen, S. B. J. Nat. Prod. 2005, 68, 1603-1609. (c) Munoz, M. A.; Munoz, O.; Joseph-Nathan, P. J. Nat. Prod. 2006, 69, 1335-1340. (d) Cerda-Garcia-Rojas, C. M.; Garcia-Gutierrez, H. A.; Hernandez-Hernandez, J. D.; Roman-Marin, L. U.; Joseph-Nathan, P. J. Nat. Prod. 2007, 70, 1167-1172. (e) Stephens, P. J.; Pan, J-J.; Devlin, F. J.; Urbanova, M.; Hajicek, J. J. Org. Chem. 2007, 72, 2508-2524. (f) Aoyagi, Y.; Yamazaki, A.; Nakatsugawa, C.; Fukaya, H.; Takeya, K. Kawauchi, S.; Izumi, H. Org. Lett. 2008, 10, 4429-4432.

(9) (a) Monde, K.; Taniguchi, T.; Miura, N.; Nishimura, S-I.; Harada, N.; Dukor, R. K.; Nafie, L. A. Tetrahedron Lett. 2003, 44, 6017-6020. (b) Min, H. M.; Aye, M.; 
Taniguchi, T.; Miura, N.; Monde, K.; Ohzawa, K.; Nikai, T.; Niwa, M.; Takaya, Y. Tetrahedron Lett. 2007, 48, 6155-6158. (c) Monde, K.; Taniguchi, T.; Miura, N.; Vairappan, C. S.; Suzuki, M. Chirality 2006, 18, 335-339.

(10) Kar, A.; Argade, N. P. Tetrahedron 2003, 59, 2991-2998.

(11) $(-)-\mathbf{1} ;[\alpha]_{\mathrm{D}}-9.4^{\mathrm{o}}($ c $0.5, \mathrm{MeOH})$. lit. ${ }^{4 \mathrm{a}}[\alpha]_{\mathrm{D}}-8^{\mathrm{o}}($ c $0.5, \mathrm{MeOH})$. $(+)-1 ;[\alpha]_{\mathrm{D}}+9.6^{\mathrm{o}}($ c $0.5, \mathrm{MeOH})$ lit. $^{2}[\alpha]_{\mathrm{D}}+15.3^{\circ}$ (c 2.0, MeOH).

(12) (a) Freedman, T. B.; Cao, X.; Phillips, L. M.; Cheng, P. T. W.; Dalterio, R.; Shu, Y-Z,; Zhang, H.; Zhao, N.; Shukla, R. B.; Tymiak, A.; Gozo, S. K.; Nafie, L. A.; Gougoutas, J. Z. Chirality 2006, 18, 746-753. (b) Urbanova, M.; Setnicka, V.; Devlin, F. J.; Stephens, P. J. J. Am. Chem. Soc. 2005, 127, 6700-6711.

(13) $2.0 \mathrm{M}$ TMS-diazomethane in hexane solution $(60 \mu \mathrm{L})$ was added to a stirred solution of (-)-1 (9 mg, $42 \mu \mathrm{mol})$ in $\mathrm{CH}_{2} \mathrm{Cl}_{2}: \mathrm{MeOH}$ (3:1). After being stirred for 0.5 $\mathrm{h}$ at room temperature, the mixture was concentrated and subjected to stationary phase HPLC on a YMC-Pack SIL column $(0.46 \mathrm{~cm} \phi \times 25 \mathrm{~cm}$, hexane:2-propanol $=$ $30: 1,0.3 \mathrm{~mL} / \mathrm{min})$, to give $1.7 \mathrm{mg}$ of $(-)-2$ as a colorless oil $(17 \%)$.

$(-)-2 ;[\alpha]_{\mathrm{D}}-18.1^{\circ}$ ( с $\left.0.2, \mathrm{MeOH}\right)$.

2.0 M TMS-diazomethane in hexane solution $(60 \mu \mathrm{L})$ was added to a stirred solution of $(+)-1(11 \mathrm{mg}, 51 \mu \mathrm{mol})$ in $\mathrm{CH}_{2} \mathrm{Cl}_{2}: \mathrm{MeOH}(3: 1)$. After being stirred for $0.5 \mathrm{~h}$ at room temperature, the mixture was concentrated and subjected to stationary phase HPLC on a YMC-Pack SIL column $(0.46 \mathrm{~cm} \phi \times 25 \mathrm{~cm}$, hexane:2-propanol = $30: 1,0.3 \mathrm{~mL} / \mathrm{min})$, to give $3.2 \mathrm{mg}$ of $(+)-2$ as a colorless oil $(25 \%)$.

$(+)-2 ;[\alpha]_{\mathrm{D}}+18.7^{\circ}($ c $0.2, \mathrm{MeOH})$.

(14) Roder, E.; Krauss, H. Liebigs Ann. Chem. 1992, 177-181.

(15) (-)-3; $[\alpha]_{\mathrm{D}}-68.3^{\circ}\left(\right.$ c $\left.0.9, \mathrm{CHCl}_{3}\right),(+)-3 ;[\alpha]_{\mathrm{D}}+71.5^{\circ}\left(\right.$ c $\left.0.9, \mathrm{CHCl}_{3}\right)$ $(-)-4 ;[\alpha]_{\mathrm{D}}-10.0^{\circ}\left(\right.$ c $\left.2.0, \mathrm{CHCl}_{3}\right),(+)-4 ;[\alpha]_{\mathrm{D}}+12.1^{\circ}\left(\right.$ c $\left.2.0, \mathrm{CHCl}_{3}\right)$

(16) See Supplementary Data. 